\title{
Analysis on the Sensitivity of Factors Influencing Natural Gas Power Generation in China
}

\author{
Gaojun Liu a, Long Jiang ${ }^{b}$, Lei Du c, Yue Guo ${ }^{d}$ and Qing Li ${ }^{\mathrm{e}}$ \\ North China Electric Power Research Institute Co. Ltd., Beijing, 100045, China. \\ aliu.gao.jun@163.com, b18810438746@163.com, 'dulei426311@163.com, \\ dhosa0603@163.com, encepri@139.com
}

Keywords: Natural gas power generation, sensitivity, economic.

\begin{abstract}
It is to guide the natural gas power generation capacity reaching 110 million $\mathrm{kw}$ in 2020 according to "Natural gas development "thirteen five" plan", and the natural gas power generation installed ratio from $4.33 \%$ in 2015 rises to $5.5 \%$ in 2020 . Benefiting from the gas and electricity reform policy, the natural gas power generation will be in the golden period of development during the 13th Five-Year time. Compared with coal-fired power generation, the economic cost of natural gas power generation is far higher. In order to further study the impact of the factors on the cost of electricity generation, we choose the price of electricity, gas prices, environmental subsidies and other factors for sensitivity analysis. The results show that the current price of electricity and gas price are the main factors that affect the economic performance of natural gas power generation, but with the gradual progress of gas reform and electricity reform, it is expected that the economy of natural gas power generation will be significantly improved.
\end{abstract}

\section{Introduction}

It is to guide the natural gas power generation capacity reaching 110 million $\mathrm{kw}$ in 2020 according to "Natural gas development "thirteen five" plan", and the natural gas power generation installed ratio from $4.33 \%$ in 2015 rises to $5.5 \%$ in 2020 . Correspondingly, the CAGR of natural gas power installed capacity is $10.63 \%$ based on the plan. Thinking about the difference between the two rates, we can find that the natural gas consumption in the power generation growth rate will be slightly higher than the growth rate of natural gas power generation capacity. In other words, the natural gas generation as the clean energy, will give the priority to development $[1,2]$.

Table 1. the capacity and rate of natural gas power generation during "thirteen five" plan

\begin{tabular}{c|c|c|c}
\hline contents & units & 2015 & 2020 \\
\hline power generation capacity & 100 million kilowatts & 15.3 & 20 \\
\hline natural gas power generation rate & $\%$ & 4.33 & 5.5 \\
\hline natural gas power generation capacity & 100 million kilowatts & 0.6637 & 1.1 \\
\hline
\end{tabular}

In order to estimate the scale of natural gas power generation during the 13th Five-Year Plan, the relevant datas of the power installed condition are calculated in this paper. The installed capacity is from the public data of "Eleventh Five-Year Plan" of "Energy Development". The installed capacity of natural gas power generation in 2015 comes from "China Electrical Engineering Society Professional Development Report (2015 - 2016) " and the natural gas power generation capacity in 2020 is from the" natural gas development "thirteen five" plan ".The installed capacity of about 43.63 million kilowatts of the increase.data can be found in the calculation of natural gas during the 13th Five-Year Plan, which scale is more than half of the installed capacity in 2015[3].

There are many factors that affect the profitability of gas power generation, such as the price of electricity, gas prices, environmental subsidies, equipment maintenance costs, personnel expenses and other factors[4,5]. Regular maintenance costs, personnel expenses and other factors are basically fixed annual expenditure, and in this paper we mainly study the price of electricity, gas prices and environmental subsidies. 


\section{Analysis on the Sensitivity of Factors}

As the operating mode of the gas power plant is mostly similar, so in this paper we choose a 38MW gas power generation for analysis.

\subsection{Analysis on Economic Profit of Gas Power Generation}

Before we calculate it, we need estimate the basic operating parameters of the power plant. We assume that the running time in a year for the plant is $8000 \mathrm{~h}$ and the turbine thermal efficiency is $9850 \mathrm{KJ} / \mathrm{kWh}$. So the annual power generation is $(38 * 1000 * 8000) 304$ million $\mathrm{kWh}$.

The operating costs and annual benefits of the gas power plant are analyzed. The results are shown in Table 2.

Table 2. the operating costs and annual benefits of the gas power plant

\begin{tabular}{|c|c|c|c|c|}
\hline contents & keys & description & fee & $\begin{array}{l}\text { total fee } \\
\qquad\left(10^{4}\right. \\
\text { CNY })\end{array}$ \\
\hline \multirow{4}{*}{ operating costs } & $\begin{array}{l}\text { maintenance } \\
\text { costs }\end{array}$ & based on empirical data. & $0.03 \mathrm{CNY} / \mathrm{kwh}$ & 912 \\
\hline & natural gas & $\begin{array}{l}\text { the power generation efficiency is } 5.324 \mathrm{kwh} / \mathrm{m}^{3} \text { and the } \\
\text { annual consumption of natural gas is } 0.571 \text { billion } \mathrm{m}^{3} \text {. }\end{array}$ & $3.65 \mathrm{CNY} / \mathrm{m}^{3}$ & 20841.5 \\
\hline & lubricating oil & the annual consumption of lubricating oil is $24 \mathrm{t}$. & $16 \mathrm{CNY} / \mathrm{kg}$ & 38.4 \\
\hline & water & the annual consumption of water is 96 thousand $t$. & $3.2 \mathrm{CNY} / \mathrm{t}$ & 30.7 \\
\hline \multicolumn{4}{|c|}{ annual total operating costs } & 21822.6 \\
\hline $\begin{array}{l}\text { income of power } \\
\text { generation }\end{array}$ & \multicolumn{3}{|c|}{$\begin{array}{c}\text { Electricity price: } 0.66 \mathrm{CNY} / \mathrm{kwh} \\
\text { income of power generation:304 million } \mathrm{kWh} * 0.66 \mathrm{CNY} / \mathrm{kwh}=200.64 \text { billion } \mathrm{CNY}\end{array}$} & 20064 \\
\hline \multicolumn{4}{|c|}{ annual total profit } & -1758.6 \\
\hline
\end{tabular}

The above analysis does not contain the environmental subsidies (calculated by the cost of 2 cents per kwh )for the gas power plant.If the gas power plant meets environmental requirements, another income of about 304 million $\mathrm{kwh} * 0.02 \mathrm{CNY} / \mathrm{kWh}=6.08$ million $\mathrm{CNY}$. The power plant is still with a loss.

\subsection{Sensitivity Analysis of Gas Power Plant on Electricity Price} 2.

In the case of sensitivity analysis, the sensitivity of the relative change is based on the data in Table

The annual income is expressed by $\mathrm{W}$, the net price is expressed by $\mathrm{X}$, and the annual income of the reference point is expressed by $\mathrm{W}_{0}$. The reference price is expressed by $\mathrm{X} 0$, the relative change of the price of the net electricity is expressed by a, and the relative change of the annual income is denoted by $\mathrm{b}$. The sensitivity coefficient is expressed by $\mathrm{M}$.

$$
\begin{gathered}
\mathrm{W}=-21822.6+30400 * \mathrm{X}+608 \\
\mathrm{a}=\frac{X-X_{0}}{X_{0}} \times 100 \% \\
\mathrm{~b}=\frac{W-W_{0}}{W_{0}} \times 100 \% \\
\mathrm{M}=\mathrm{b} / \mathrm{a}
\end{gathered}
$$

Table 3. the sensitivity analysis on the net electricity price

\begin{tabular}{c|c|c|c|c|c|c|c|c}
\hline $\mathrm{X}$ & 0.462 & 0.528 & 0.594 & 0.66 & 0.726 & 0.792 & 0.858 & $\mathrm{CNY} / \mathrm{kwh}$ \\
\hline $\mathrm{a}$ & $-30.0 \%$ & $-20.0 \%$ & $-10.0 \%$ & $0.0 \%$ & $10.0 \%$ & $20.0 \%$ & $30.0 \%$ & $\%$ \\
\hline $\mathrm{W}$ & -7169.8 & -5163.4 & -3157 & -1150.6 & 855.8 & 2862.2 & 4868.6 & $10^{4} \mathrm{CNY}$ \\
\hline $\mathrm{b}$ & $-523.1 \%$ & $-348.8 \%$ & $-174.4 \%$ & $0.0 \%$ & $174.4 \%$ & $348.8 \%$ & $523.1 \%$ & $\%$ \\
\hline $\mathrm{M}$ & 17 & 17 & 17 & $/$ & 17 & 17 & 17 & $/$ \\
\hline
\end{tabular}

Through the sensitivity analysis of gas power generation factors, it is found that the electricity price is very sensitive to the influence of gas power generation. At present, the local governments encourage the gas power plant in different levels, which results in electricity prices affecting corporate earnings in a great degree. If the governments cancel this support efforts for the gas power generation, there is no obvious advantage than coal-based plants. 


\subsection{Sensitivity Analysis of Gas Power Plant on Gas Price}

By gas transportation costs, market demand, gas quality and other effects, the major gas prices in major regions are quite different. Gas prices are also an important factor affecting the overall profitability of gas power plants.

In the case of sensitivity analysis, the sensitivity of the relative change is based on the data in Table 2.

The annual income is expressed by $\mathrm{W}$, the gas price is expressed by $\mathrm{Z}$, and the annual income of the reference point is expressed by $\mathrm{W}_{0}$. The reference price is expressed by $\mathrm{Z}_{0}$, the relative change of the price of the gas is expressed by $d$, and the relative change of the annual income is denoted by $b$. The sensitivity coefficient is expressed by $M$.

$$
\begin{aligned}
& \mathrm{W}=-5710 * \mathrm{Z}+30400 * 0.66+608-(912+38.4+30.7) \\
& \mathrm{d}=\frac{Z-Z_{0}}{Z_{0}} \times 100 \% \\
& \mathrm{~b}=\frac{W-W_{0}}{W_{0}} \times 100 \% \\
& \mathrm{M}=\mathrm{d} / \mathrm{a}
\end{aligned}
$$

Table 4 the sensitivity analysis on the gas price

\begin{tabular}{c|c|c|c|c|c|c|c|c}
\hline $\mathrm{Z}$ & 2.56 & 2.92 & 3.29 & 3.65 & 4.02 & 4.38 & 4.75 & $\mathrm{CNY} / \mathrm{kwh}$ \\
\hline $\mathrm{d}$ & $-30.0 \%$ & $-20.0 \%$ & $-10.0 \%$ & $0.0 \%$ & $10.0 \%$ & $20.0 \%$ & $30.0 \%$ & $\%$ \\
\hline $\mathrm{W}$ & 5101.85 & 3017.7 & 933.55 & -1150.6 & -3234.75 & -5318.9 & -7403.05 & $10^{4} \mathrm{CNY}$ \\
\hline $\mathrm{b}$ & $-543.4 \%$ & $-362.3 \%$ & $-181.1 \%$ & $0.0 \%$ & $181.1 \%$ & $362.3 \%$ & $543.4 \%$ & $\%$ \\
\hline $\mathrm{M}$ & 18 & 18 & 18 & $/$ & 18 & 18 & 18 & $/$ \\
\hline
\end{tabular}

It can be found that the gas price has a significant impact on the gas power plant profit, which is very sensitive. However, due to the regional different natural gas prices, the profit of gas power plant is significantly affected by the local gas supply price.

\subsection{Sensitivity Analysis of Gas Power Plant on Environmental Subsidies}

In the case of sensitivity analysis, the sensitivity of the relative change is based on the data in Table 2.

The annual income is expressed by $\mathrm{W}$, the environmental subsidies is expressed by $\mathrm{Y}$, and the annual income of the reference point is expressed by $\mathrm{W}_{0}$. The reference price is expressed by $\mathrm{Y}_{0}$, the relative change of the price of the gas is expressed by c, and the relative change of the annual income is denoted by $\mathrm{b}$. The sensitivity coefficient is expressed by $\mathrm{M}$.

$$
\begin{aligned}
& \mathrm{W}=-21822.6+30400 * 0.66+30400 * \mathrm{Y} \\
& \mathrm{c}=\frac{Y-Y_{0}}{Y_{0}} \times 100 \% \\
& \mathrm{~b}=\frac{W-W_{0}}{W_{0}} \times 100 \% \\
& \mathrm{M}=\mathrm{b} / \mathrm{c}
\end{aligned}
$$

Table 5 . the sensitivity analysis on the environmental subsidies

\begin{tabular}{c|c|c|c|c|c|c|c|c}
\hline $\mathrm{Y}$ & 0.02 & 0.03 & 0.04 & 0.05 & 0.06 & 0.07 & 0.08 & $\mathrm{CNY} / \mathrm{kwh}$ \\
\hline $\mathrm{c}$ & $0.0 \%$ & $50.0 \%$ & $100.0 \%$ & $150.0 \%$ & $200.0 \%$ & $250.0 \%$ & $300.0 \%$ & $\%$ \\
\hline $\mathrm{W}$ & -1150.6 & -846.6 & -542.6 & -238.6 & 65.4 & 369.4 & 673.4 & $10^{4} \mathrm{CNY}$ \\
\hline $\mathrm{b}$ & $0.0 \%$ & $26.4 \%$ & $52.8 \%$ & $79.3 \%$ & $105.7 \%$ & $132.1 \%$ & $158.5 \%$ & $\%$ \\
\hline $\mathrm{M}$ & $/$ & 0.53 & 0.53 & 0.53 & 0.53 & 0.53 & 0.53 & $/$ \\
\hline
\end{tabular}

From the table 5 , it can be discovered that the coefficient of the sensitivity analysis on the environmental subsidies is only 0.53. Environmental subsidies have a certain impact, but it is not sensitive.

\section{Summary}

At present, the costs of China's natural gas power generation are obviously higher than coal-fired power generation's. But benefiting from environmental policy, gas power generation in the eastern China is under the better development.

Economic benefits from the natural gas power generation is significantly affected by the net electricity price and gas prices, and poorly affected by environmental subsidies. In the case the 
sensitivity coefficient is above 17 for the first two and the last one corresponds to the sensitivity coefficient of 0.53 .

The main factors of the current domestic natural gas power generation are the price of electricity and gas price. With the development of the electric reform and gas reform under the dual drive, the Chinese natural gas power generation maybe rapidly expansion.

\section{References}

[1]. Jiping Pan, Yu Lou, Luxin Wang. Target post-evaluation of China's "12th Five-Year" oil and gas exploration and development planning and its "13th Five-Year" target prediction[J]. Natural Gas Industry, 2016, 3(2):108-116.

[2]. Kang Z. Natural gas supply-demand situation and prospect in China [J]. Natural Gas Industry B, 2014, 1(1):103-112.

[3]. Ma X, Liu Z. Application of a novel time-delayed polynomial grey model to predict the natural gas consumption in China [J]. Journal of Computational \& Applied Mathematics, 2017.

[4]. Zhang Q. China's Natural Gas Strategy: Arrangement, Reform and Future Trends [J]. Frontiers, 2016.

[5]. Jiang Z, Wang F, Duan Y, et al. China's gas market under new situations: Trends and countermeasures - Taking Sichuan and Chongqing gas provinces as an example [J]. Natural Gas Industry, 2016. 